\title{
Aggregation Kinetics for Monoclonal Antibody Products
}

\author{
Ishan Arora, Rohit Bansal, Varsha Joshi, and Anurag S. Rathore
}

\begin{abstract}
Monoclonal antibodies have emerged as a valuable class of therapeutic products. However, the industry still faces pertinent challenges with respect to product stability, particularly product aggregation that leads to toxicity and immunogenicity. The present project is an attempt to propose a kinetic model for the aggregation of monoclonal antibodies using the analysis of experiments that were performed for several different combinations of buffer type, temperature, $\mathrm{pH}$ and salt concentration pertaining to three types of chromatography - protein A chromatography, cation exchange chromatography and anion exchange chromatography. Modified Lumry Eyring model has been employed by taking into account the reversibility of each step in the aggregation process. MATLAB R2011b has been used to find the optimum values of the kinetic rate constants for the different cases. The model can go a long way in reducing the extent of aggregation by helping to accurately choose the experimental conditions with the minimum number of experiments.
\end{abstract}

Index Terms-Aggregates, chromatography, Lumry Eyring model, monoclonal antibodies.

\section{INTRODUCTION}

Hundreds of monoclonal antibodies (mAbs) are either currently on the market or under development. They have been successfully introduced as therapies to a variety of diseases such as rheumatoid arthritis, multiple sclerosis and different forms of cancer. However, the industry still faces challenges with respect to product stability, particularly protein aggregation that is one of the major road barriers inhibiting the rapid commercialization of potential protein drug candidates. Aggregates can cause loss of activity as well as toxicity and immunogenicity. Because of their toxic potential, aggregates can cause an unwanted response or even overreaction of a patient's immune system. In fact, abnormal protein folding leading to its aggregation is very common in many human diseases resulting from various genetic as well as physical and chemical changes inside a cell [1].

Protein molecules can aggregate by physical association without any change in primary structure or by chemical bond formation and may lead to the formation of either soluble or insoluble aggregates. Aggregation can occur through a variety of mechanisms - Reversible association of the native monomer, aggregation of conformationally altered monomer, aggregation of chemically modified product, nucleation-controlled aggregation, surface induced aggregation etc. which are illustrated in Fig. 1 [2].

Manuscript received December 25, 2013; revised March 4, 2014

Ishan Arora, Rohit Bansal, Varsha Joshi, and Anurag S. Rathore are with the Department of Chemical Engineering, Indian Institute of Technology, Delhi, India (e-mail: amiarora2011@gmail.com).

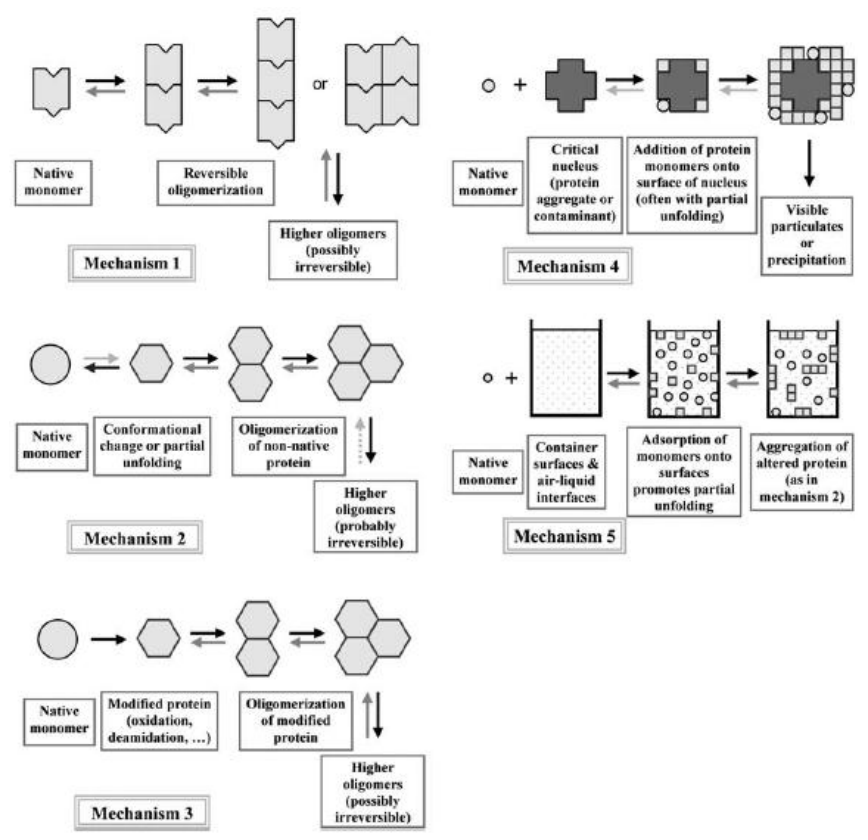

Fig. 1. Schematic illustration of common aggregation mechanisms [2].

The extent of aggregation depends on many factors which can be broadly classified as intrinsic (primary, secondary, tertiary or quaternary structure) or extrinsic (protein environment, processing conditions) [3]. Proteins in general are commonly known to aggregate under low $\mathrm{pH}$ conditions. During processing, there may be changes in protein environment such as changes in $\mathrm{pH}$, buffer concentration, ionic concentration etc. The environmental factors affect at a molecular level the protein-protein and protein-salt interactions.

It is extremely important to understand the mechanism of protein aggregation since the limited success in controlling aggregation is primarily due to the lack of a concrete understanding of the aggregation process. Kinetic studies and data curve fitting are keys to rigorous mechanistic studies [4]. When combined with experimental kinetic and thermodynamic data, models of aggregation kinetics can provide a unique and noninvasive way to gain qualitative and quantitative details about the aggregation mechanism and also help in the design of experiments and additives to more accurately predict or control aggregation rates [5]. The hold time of the monoclonal antibody in the buffer can be appropriately chosen depending on its aggregation behavior in order to minimize the formation of aggregates.

The primary objective of this project was to use the experimental analysis together with the knowledge of chemical kinetics to build a kinetic model for protein aggregation and to correlate it with several key factors which influence aggregation such as buffer type, temperature, $\mathrm{pH}$ and salt concentration. The currently established purification platform for monoclonal antibodies 
typically employs three chromatography steps with Protein A chromatography as the initial capture step followed by two polishing steps which generally include at least one Ion Exchange Chromatography step. Hence, this work focused on studying the buffers commonly employed in these purification processes and analyzing the stability of the monoclonal antibody under conditions typically employed in the industry for the different types of chromatography.

\section{LITERATURE REVIEW}

Several models have been proposed in the literature for explaining the kinetics of protein aggregation. These fall into different categories:

1) Lumry-Eyring model, according to which a native protein unfolds in a reversible way into an unfolded state which then aggregates irreversibly [6], [7]

2) Native polymerization models, in which nucleation and polymer growth are treated in detail, but conformational changes prior to or during assembly are not included [5], [8]

3) Extended Lumry-Eyring models, in which aggregation kinetics observed experimentally, are described as a combination of reversible conformational transitions and the intrinsic kinetics via non native states. However, in contrast to classical Lumry Eyring model, these models include a detailed description of the intrinsic aggregation kinetics [9]

4) Aggregate condensation and polymerization models, which specifically take care of the higher order assembly of aggregates that are formed during the initial steps of nucleation and polymerization [5], [10]

The modified Lumry Eyring kinetic model has been successfully used by researchers to describe the monoclonal antibody aggregation process at low $\mathrm{pH}$ (3-4) [6]. A mathematical model of non-native protein aggregation has also been presented which combines the Lumry Eyring and Nucleated Polymerization (LENP) descriptions that is useful under conditions where detailed kinetics of folding or unfolding can be neglected [5]. However, a detailed study of aggregation behavior of monoclonal antibodies at several different conditions of $\mathrm{pH}$, temperature and salt molarity pertaining to different types of chromatography could not be found in the literature and this work is an attempt to address the same by analyzing the stability of monoclonal antibodies under the different experimental conditions employed for Protein A chromatography, Cation Exchange Chromatography and Anion Exchange Chromatography.

\section{MATERIALS AND EXPERIMENTAL PROTOCOLS}

\section{A. Feed Material}

The monoclonal antibody IgG1 (pI between 8.2 and 8.5 ) used in the experiments was obtained from a major biotech company. The antibody stock was stored at $4^{\circ} \mathrm{C}$ as a 37 $\mathrm{mg} / \mathrm{mL}$ solution in $15 \mathrm{mM}$ sodium phosphate with $150 \mathrm{mM}$ $\mathrm{NaCl}$ at $\mathrm{pH} 7$ in aliquots.

\section{B. Reagents}

The buffers used for the experiments were procured from Merck, India. All buffers were filtered with $0.22 \mu \mathrm{m}$ nylon membrane filter and degassed. All SEC reagents were HPLC purity grade and purchased from Sigma Aldrich, India.

\section{Sample Preparation}

Solutions for the aggregation studies were prepared from IgG stock aliquots by performing buffer exchange of $1 \mathrm{~mL}$ formulated solution into $3 \mathrm{~mL}$ of the solution of interest. Protein concentration was measured by UV-spectroscopy at a wavelength of $280 \mathrm{~nm}$. Following the buffer exchange step, $1.5 \mathrm{~mL}$ samples were stored at $4^{\circ} \mathrm{C}$ and $30^{\circ} \mathrm{C}$ respectively. Analysis of samples at both temperatures was performed at $0 \mathrm{~h}$ (hours), $6 \mathrm{~h}, 24 \mathrm{~h}, 72 \mathrm{~h}, 120 \mathrm{~h}$ and $168 \mathrm{~h}$. All the samples were characterized for stability using Size Exclusion Chromatography (SEC).

\section{Buffer Exchange}

A SephadexG-25 resin (GE Healthcare) was packed into a Tricon $^{\mathrm{TM}}$ column $(100 \times 10 \mathrm{~mm})$. The column was equilibrated with the buffer of interest till the $\mathrm{pH}$ and conductivity reached the desired value. The mAb (37 $\mathrm{mg} / \mathrm{mL}$ ) to be buffer exchanged was loaded on the column and eluted with the required buffer. The eluent was collected and the $\mathrm{mAb}$ concentration was adjusted to $10 \mathrm{mg} / \mathrm{mL}$ by dilution with the respective buffer.

\section{E. Size Exclusion Chromatography (SEC)}

Size Exclusion Chromatography was carried out using Agilent 1200 infinite series HPLC unit having quaternary pump with degasser, an auto-sampler with cooling unit maintained at $4^{\circ} \mathrm{C}$ and a VWD detector. The column used was a BioSuite ${ }^{\mathrm{TM}} 250,5 \mu \mathrm{m}$, of $7.8 \mathrm{~mm} \times 300 \mathrm{~mm}$ dimensions (Waters Corporation, Milford, MA, United States) operated at $25^{\circ} \mathrm{C}$. Each sample was eluted isocratically over 17 minutes at a constant flow rate of 0.8 $\mathrm{mL} / \mathrm{min}$. The mobile phase was a solution of $100 \mathrm{mM}$ Phosphate buffer with $100 \mathrm{mM} \mathrm{Na} \mathrm{SO}_{4}$ at $\mathrm{pH}$ 6.8. The buffer was degassed and filtered with $0.22 \mu \mathrm{m}$ nylon membrane. Monomer content was estimated by calculating the percentage area under the monomer peak using Agilent Chemstation software.

\section{F. Design of Experiments}

Aggregation behavior of monoclonal antibodies was observed under different conditions of buffer type, temperature, $\mathrm{pH}$ and salt concentration using Size exclusion chromatography. Five buffer systems frequently employed in the downstream processing of monoclonal antibodies were selected for study - Citrate $(20 \mathrm{mM}$ and $100 \mathrm{mM})$, Acetate $(25 \mathrm{mM}$ and $100 \mathrm{mM})$, Glycine $(100 \mathrm{mM})$, Phosphate $(15 \mathrm{mM})$ and Tris-HCl $(20 \mathrm{mM})$. Elution in Protein A Chromatography is typically performed at low $\mathrm{pH}$ as it is followed by viral inactivation. Since most host cell proteins are more acidic than the therapeutic human or humanized $\mathrm{mAb}$ and many mAbs have isoelectric points between 8 and 9, the Anion Exchange Chromatography flow-through step is usually operated at a loading $\mathrm{pH}$ between 7 and 8 . The details of the design of experiments can be found in Table I. After performing Size Exclusion Chromatography, the \% HMW (High Molecular Weight) i.e. the percentage of aggregates was obtained for each case and plotted against time. The buffers for Protein A chromatography are Glycine 
and also Citrate and Acetate at low $\mathrm{pH}$ while Phosphate buffer and Citrate and Acetate buffer at high $\mathrm{pH}$ could be employed for Cation Exchange chromatography. Tris- $\mathrm{HCl}$ is a commonly used buffer for Anion Exchange Chromatography.

TABLE I: SUMMARY of EXPERIMENTS

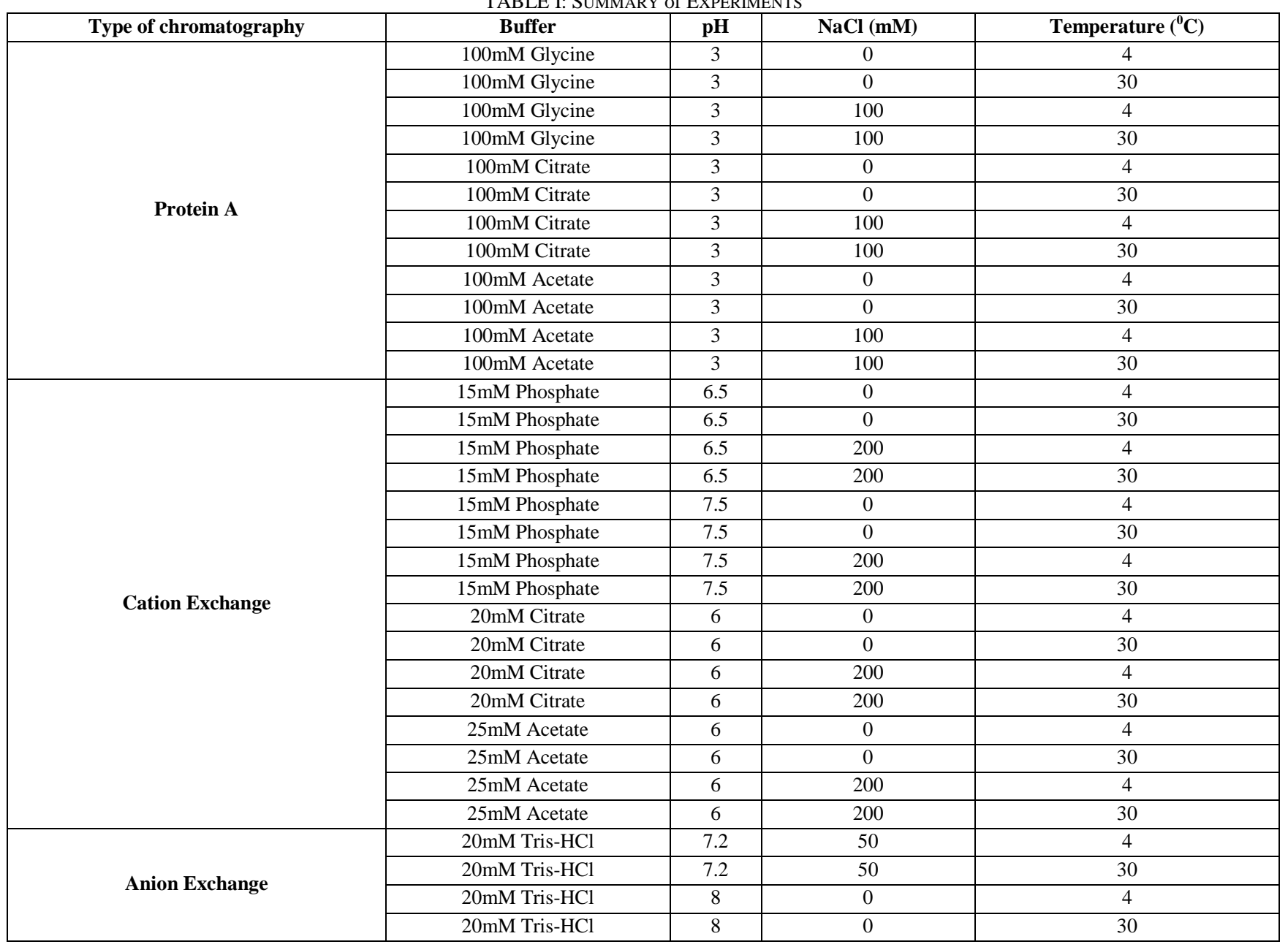

\section{MODELING}

Based on the analysis of several kinetic models proposed in the literature, the model which is most widely accepted and seemed most suitable for these conditions is the LumryEyring model but with some modifications such as taking into account the reversibility of each step which was not taken into account in the original Lumry Eyring model but has been subsequently observed in various studies. Fig. 2 shows the scheme of the aggregation process based on the modified Lumry Eyring model used in this work.

$$
\begin{gathered}
N \underset{K_{e q}}{\stackrel{K_{e q}}{\rightleftarrows}} I \\
\left.I+I \underset{K_{-1}}{\stackrel{k_{1}}{\rightleftarrows}}\right)_{e q}=\frac{k_{\text {un }}}{k_{\text {fold }}} \\
I+D \underset{k_{-2}}{\stackrel{k_{2}}{\rightleftarrows}} T
\end{gathered}
$$

Fig. 2. Scheme of aggregation process based on modified Lumry Eyring model [6].

The assumptions made in the model are:
1) Trimers, (T) have been considered as the largest species present in the system. The motivation behind this assumption is that the observed oligomers larger than trimer are generally negligible

2) It is assumed that a unique reactive intermediate, (I) is present which is prone to aggregation and the intermediate, (I) and native, $(\mathrm{N})$ can reach thermodynamic equilibrium instantaneously

3) It has been assumed that two intermediate, (I) species can aggregate to form a dimer, (D) and trimers, (T) are formed by subsequent addition of an (I) unit. Aggregation between two oligomers has been neglected

The following kinetic equations were obtained using the reaction scheme in Fig. 2:

$$
\begin{gathered}
\frac{d[N]}{d t}=-k_{\text {unf }}[N]+k_{\text {fold }}[I] \\
\frac{d[I]}{d t}=k_{\text {unf }}[N]-k_{\text {fold }}[I]-2 k_{1}[I]^{2}+2 k_{-1}[D] \\
-k_{2}[I][D]+k_{-2}[T] \\
\frac{d[D]}{d t}=k_{1}[I]^{2}-k_{-1}[D]-k_{2}[I][D]+k_{-2}[T] \\
\frac{d[T]}{d t}=k_{2}[I][D]-k_{-2}[T]
\end{gathered}
$$

From the experimental analysis, it is not possible to 
distinguish between the $(\mathrm{N})$ and the $(\mathrm{I})$ species since the only measurable quantity is the total monomer concentration, [M].

$$
\begin{gathered}
{[M]=[N]+[I]} \\
{[I]=[M] \times f} \\
f=\frac{K_{e q}}{1+K_{e q}}
\end{gathered}
$$

Apparent rate constants are defined as follows:

$$
\begin{aligned}
& k_{1, \text { app }}=f^{2} \times k_{1} \\
& k_{2, a p p}=f^{2} \times k_{2}
\end{aligned}
$$

These substitutions are used in the earlier equations (1) (4) to arrive at the following equations:

$$
\begin{gathered}
\frac{d[M]}{d t}=-2 k_{1, a p p}[M]^{2}+2 k_{-1}[D]-k_{2, a p p}[M][D] \\
+k_{-2}[T] \\
\frac{d[D]}{d t}=k_{1, a p p}[M]^{2}-k_{-1}[D]-k_{2, a p p}[M][D]+k_{-2}[T] \\
\frac{d[T]}{d t}=k_{2, a p p}[M][D]-k_{-2}[T]
\end{gathered}
$$

The apparent rate constants are the product of two terms, each of which represents a main aspect of the process. $f$ describes the conformational stability behavior of the protein and the intrinsic rate constants, $k_{1}$ and $k_{2}$ denote the kinetic colloidal stability of the solution.

These are a system of coupled first order ordinary differential equations which were solved using MATLAB R2011b. The methodology adopted for solving these equations using MATLAB was as follows:

1. Finding the initial estimates for the kinetic rate constants using the procedure highlighted in section V-B and defining the cumulative error by using experimental data

2. Creating a problem structure in MATLAB by defining objective function (cumulative error), local solver (fmincon), algorithm (Interior Point), start point (initial estimates from Step 1), derivatives (approximated by solver), constraints (non-negative constraint) etc.

3. Running the solver and exporting problem and options to the MATLAB structure

4. Creating a solver object (GlobalSearch object)

5. Running the solver to get the global minimum error

\section{RESULTS AND DISCUSSIONANALYSIS OF EXPERIMENTAL DATA}

As can be observed in the plots of the total aggregate percentage vs time for the different cases (Fig. 3-Fig. 5), Citrate buffer has shown aggregation in all the cases in conditions pertaining to Protein A chromatography while in the case of Acetate buffer aggregation has been observed in the presence of $100 \mathrm{mM} \mathrm{NaCl}$ at both $4^{\circ} \mathrm{C}$ and $30^{\circ} \mathrm{C}$. Glycine buffer has also shown aggregation at pH 3, $100 \mathrm{mM}$ salt concentration at both $4^{\circ} \mathrm{C}$ and $30^{\circ} \mathrm{C}$. Aggregation at low $\mathrm{pH}$ is attributed to the structural changes that occur in the $\mathrm{Fc}$ domain of $\mathrm{mAb}$ which ultimately lead to the formation of soluble high molecular weight aggregates or insoluble precipitates during elution [6], [7]. Aggregation is generally favored by increase in temperature because heat can trigger the initial conformational change [2]. In all buffers other than Citrate, with no salt present in the system there is negligible, if any, increase in the concentration of aggregates, both at $4^{\circ} \mathrm{C}$ and $30^{\circ} \mathrm{C}$. Hence, the presence of salt $(\mathrm{NaCl})$ seems to facilitate the process of aggregation under these conditions. For phosphate buffer, the mAb has been found to be stable under all conditions. This suggests that high $\mathrm{pH}$ seriously hinders aggregation. In Tris- $\mathrm{HCl}$, the $\mathrm{mAb}$ is stable at both temperatures $\left(4^{\circ} \mathrm{C}\right.$ and $\left.30{ }^{\circ} \mathrm{C}\right)$ at 50 $\mathrm{mM}$ concentration of $\mathrm{NaCl}$ and $\mathrm{pH}$ 7.2. However, significant aggregation has been observed at $\mathrm{pH} 8$ and temperature $30{ }^{\circ} \mathrm{C}$ with no salt present in the system.

\section{Estimation of Kinetic Rate Constants}

Now that all those cases had been identified where aggregation was significant, the next step was to find suitable initial values for the four kinetic rate constants since these would be required to solve the kinetic equations in MATLAB. Hence, the equations were first simplified by making certain assumptions and graphical solution was then employed.

At $t \rightarrow 0$, it can be assumed that the only species present in the system are monomers and dimers, while trimers are negligible. Thus, using equations (10) - (12)

$$
\frac{d[M]}{d t}=-2 k_{1, a p p}[M]^{2}
$$

On integrating this equation,

$$
\frac{1}{[M]}-\frac{1}{\left[M_{0}\right]}=2 k_{1, a p p} t
$$

Here $\left[M_{0}\right]$ is the concentration of total monomers at $t=0$

Hence, if $\frac{1}{[M]}-\frac{1}{\left[M_{0}\right]}$ is plotted vs $t$, it should be a straight line whose slope can help us find the value of $k_{1, \text { app }}$. This procedure was carried out for all the cases where aggregation was significant which had been identified earlier. Now once $k_{1, \text { app }}$ had been evaluated for the different cases, the following equations (15) and (16) were obtained using (10) - (12) to estimate the other rate constants and (17) is based on a mass balance:

For $k_{-1}$,

$$
\frac{d[D]}{d t}+\frac{d[T]}{d t}=k_{1, a p p}[M]^{2}-k_{-1}[D]
$$

For $k_{2, \text { app }}$ and $k_{-2}$,

$$
\begin{gathered}
\frac{d[M]}{d t}+2 \frac{d[D]}{d t}=-3 k_{2, \text { app }}[M][D]+3 k_{-2}[T] \\
\frac{d[M]}{d t}=\frac{1}{2} \frac{d[D]}{d t}+\frac{1}{3} \frac{d[T]}{d t}
\end{gathered}
$$

Using this approach, the initial estimates for the kinetic rate constants were obtained for the different cases which are shown in Table II.

Then these initial estimates were used together with the solution methodology outlined earlier to arrive at the optimum values of the kinetic rate constants for the different cases which are depicted in Table III. The values of the 
kinetic constants for the various cases are compared in Fig. 6 to study their dependence on the operating conditions buffer type, temperature, $\mathrm{pH}$ and salt concentration.

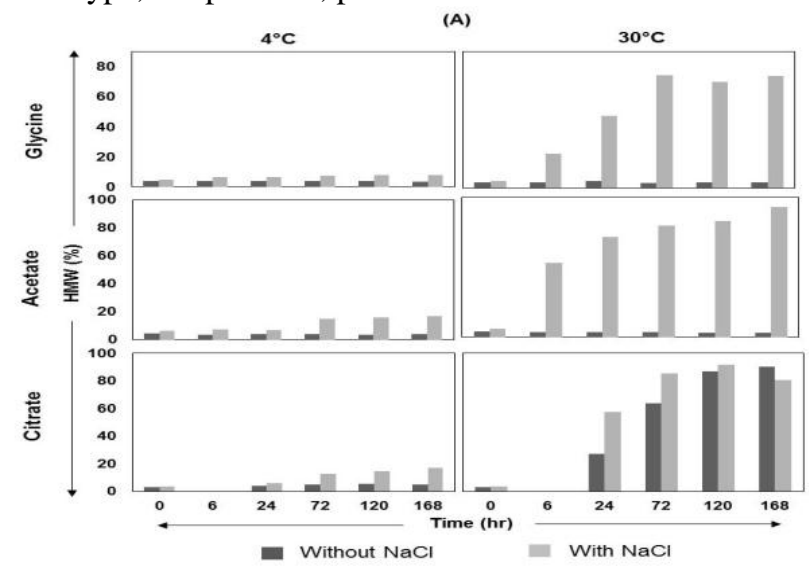

Fig. 3. Total aggregate content as a function of time for Protein A Chromatography buffers.

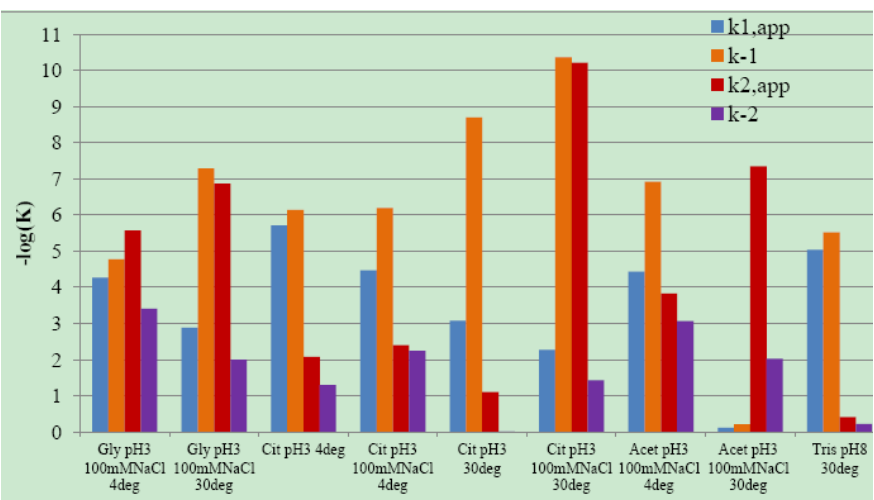

Fig. 6. Comparison of kinetic rate constants for the different cases.

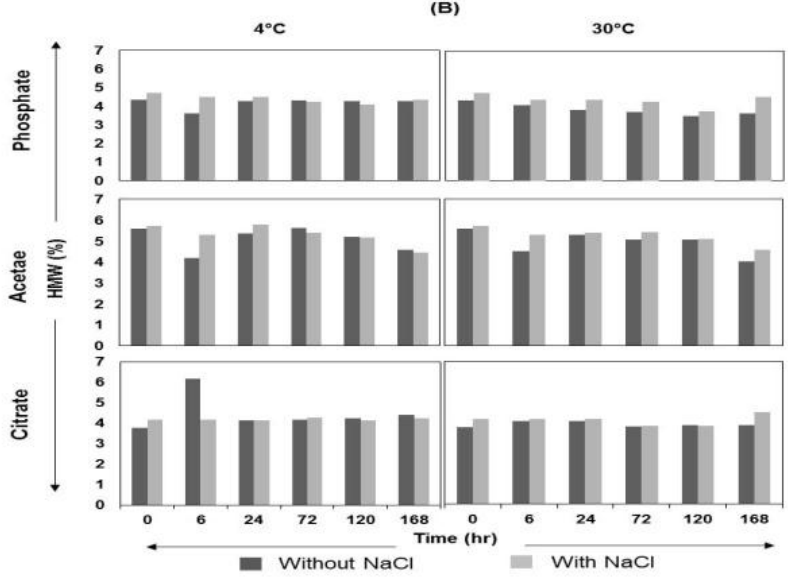

Fig. 4. Time evolution of total aggregate content for Cation Exchange Chromatography buffers.

$4^{\circ} \mathrm{C}$

$30^{\circ} \mathrm{C}$

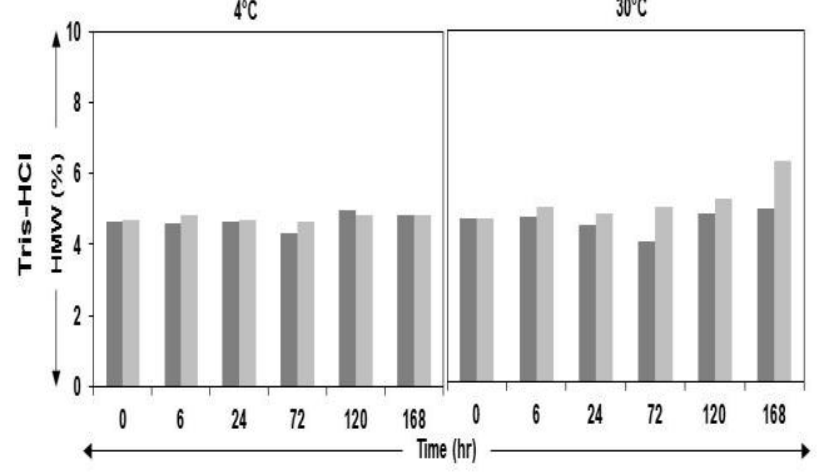

| $20 \mathrm{mll}$ pH 7.2 Tris with $50 \mathrm{mM}$ NaCl || $20 \mathrm{mll}$ pH 8 Tris

Fig. 5. Total aggregate content vs time for Anion Exchange Chromatography buffers.

TABLE II: INITIAL ESTIMATES OF KiNETIC RATE CONSTANTS

\begin{tabular}{|c|c|c|c|c|c|c|c|}
\hline Buffer & $\mathbf{p H}$ & $\mathrm{NaCl}(\mathrm{mM})$ & Temperature $\left({ }^{0} \mathrm{C}\right)$ & $\begin{array}{c}\mathbf{k}_{1, \text { app }} \\
\left.\text { (in } \mathbf{L}^{-1} \mathbf{h}^{-1}\right)\end{array}$ & $\begin{array}{c}k_{-1} \\
\left(\text { in h }^{-1}\right) \\
\end{array}$ & $\begin{array}{c}\mathbf{k}_{2, \text { app }} \\
\left.\text { (in } \mathbf{L}^{-1} \mathbf{h}^{-1}\right)\end{array}$ & $\begin{array}{c}\mathbf{k}_{-2} \\
\left(\text { in h}^{-1}\right) \\
\end{array}$ \\
\hline $\begin{array}{l}100 \mathrm{mM} \\
\text { Glycine }\end{array}$ & 3 & 100 & 4 & $5.00 \times 10^{-6}$ & $4.82 \times 10^{-6}$ & $1.82 \times 10^{-5}$ & $5.43 \times 10^{-4}$ \\
\hline $\begin{array}{l}100 \mathrm{mM} \\
\text { Glycine }\end{array}$ & 3 & 100 & 30 & $1.00 \times 10^{-3}$ & $9.58 \times 10^{-7}$ & $1.39 \times 10^{-6}$ & $2.38 \times 10^{-2}$ \\
\hline $100 \mathrm{mM}$ Citrate & 3 & 0 & 4 & $1.50 \times 10^{-6}$ & $9.23 \times 10^{-6}$ & $4.12 \times 10^{-3}$ & $2.81 \times 10^{-3}$ \\
\hline 100mM Citrate & 3 & 100 & 4 & $5.00 \times 10^{-5}$ & $7.51 \times 10^{-6}$ & $8.90 \times 10^{-4}$ & $4.21 \times 10^{-3}$ \\
\hline 100mM Citrate & 3 & 0 & 30 & $3.50 \times 10^{-3}$ & $3.37 \times 10^{-8}$ & $6.40 \times 10^{-2}$ & $4.26 \times 10^{-1}$ \\
\hline $100 \mathrm{mM}$ Citrate & 3 & 100 & 30 & $6.00 \times 10^{-3}$ & $8.79 \times 10^{-9}$ & $4.37 \times 10^{-8}$ & $9.52 \times 10^{-2}$ \\
\hline $100 \mathrm{mM}$ Acetate & 3 & 100 & 4 & $5.00 \times 10^{-5}$ & $7.63 \times 10^{-7}$ & $1.26 \times 10^{-5}$ & $1.94 \times 10^{-3}$ \\
\hline $100 \mathrm{mM}$ Acetate & 3 & 100 & 30 & $1.50 \times 10^{-3}$ & $8.47 \times 10^{-3}$ & $6.97 \times 10^{-6}$ & $2.51 \times 10^{-2}$ \\
\hline 20mM Tris- $\mathrm{HCl}$ & 8 & 0 & 30 & $3.00 \times 10^{-5}$ & $5.68 \times 10^{-3}$ & $2.16 \times 10^{-3}$ & $3.27 \times 10^{-2}$ \\
\hline
\end{tabular}

TABLE III: OPTIMUM VALUES OF KINETIC RATE CONSTANTS

\begin{tabular}{|c|c|c|c|c|c|c|c|c|c|}
\hline Buffer & pH & $\begin{array}{l}\mathrm{NaCl} \\
(\mathrm{mM})\end{array}$ & $\begin{array}{c}\text { Temp } \\
\left({ }^{0} \mathbf{C}\right)\end{array}$ & $\begin{array}{l}\mathbf{k}_{1, \text { app }} \\
\left(\text { in } \mathbf{L}^{-1} \mathbf{g}^{-1}\right)\end{array}$ & $\begin{array}{c}\mathbf{k}_{-1} \\
\left(\text { in }^{-1}\right)\end{array}$ & $\begin{array}{c}\mathbf{K}_{1}=\mathbf{k}_{1, a p p} / \mathbf{k}_{1} \\
\left(\text { in } \mathbf{L} \mathbf{g}^{-1} \text { ) }\right. \\
\text { (Equilibrium } \\
\text { Constant for } \\
\text { dimer formation) }\end{array}$ & $\left.\underset{(\text { in }}{\mathbf{k}_{2, \text { app }}} \mathbf{g}^{-1} \mathbf{h}^{-1}\right)$ & $\begin{array}{c}\mathbf{k}_{-2} \\
\left(\text { in }^{-1}\right)\end{array}$ & $\begin{array}{c}\mathbf{K}_{2}=\mathbf{k}_{2, \text {,app }} / \mathbf{k}_{2} \\
\left(\text { in } \mathbf{L ~}^{-1} \text { ) }\right. \\
\text { (Equilibrium } \\
\text { Constant for } \\
\text { trimer formation) }\end{array}$ \\
\hline $\begin{array}{l}100 \mathrm{mM} \\
\text { Glycine }\end{array}$ & 3 & 100 & 4 & $5.32 \times 10^{-5}$ & $1.67 \times 10^{-5}$ & 3.19 & $2.66 \times 10^{-6}$ & $3.90 \times 10^{-4}$ & $6.82 \times 10^{-3}$ \\
\hline $\begin{array}{l}100 \mathrm{mM} \\
\text { Glycine }\end{array}$ & 3 & 100 & 30 & $1.30 \times 10^{-3}$ & $5.09 \times 10^{-8}$ & $2.55 \times 10^{4}$ & $1.35 \times 10^{-7}$ & $1.00 \times 10^{-2}$ & $1.35 \times 10^{-5}$ \\
\hline 100mM Citrate & 3 & 0 & 4 & $1.95 \times 10^{-6}$ & $7.24 \times 10^{-7}$ & 2.69 & $8.35 \times 10^{-3}$ & $5.07 \times 10^{-2}$ & $1.65 \times 10^{-1}$ \\
\hline
\end{tabular}




\begin{tabular}{|c|c|c|c|c|c|c|c|c|c|}
\hline $100 \mathrm{mM}$ Citrate & 3 & 100 & 4 & $3.38 \times 10^{-5}$ & $6.43 \times 10^{-7}$ & $5.26 \times 10^{1}$ & $3.94 \times 10^{-3}$ & $5.67 \times 10^{-3}$ & $6.95 \times 10^{-1}$ \\
\hline $100 \mathrm{mM}$ Citrate & 3 & 0 & 30 & $8.36 \times 10^{-4}$ & $2.00 \times 10^{-9}$ & $4.18 \times 10^{5}$ & $7.89 \times 10^{-2}$ & $9.74 \times 10^{-1}$ & $8.10 \times 10^{-2}$ \\
\hline $100 \mathrm{mM}$ Citrate & 3 & 100 & 30 & $5.34 \times 10^{-3}$ & $4.35 \times 10^{-11}$ & $1.23 \times 10^{8}$ & $5.95 \times 10^{-11}$ & $3.72 \times 10^{-2}$ & $1.59 \times 10^{-9}$ \\
\hline $\begin{array}{c}100 \mathrm{mM} \\
\text { Acetate }\end{array}$ & 3 & 100 & 4 & $3.64 \times 10^{-5}$ & $1.20 \times 10^{-7}$ & $3.03 \times 10^{2}$ & $1.49 \times 10^{-4}$ & $8.63 \times 10^{-4}$ & $1.73 \times 10^{-1}$ \\
\hline $\begin{array}{c}100 \mathrm{mM} \\
\text { Acetate }\end{array}$ & 3 & 100 & 30 & $7.64 \times 10^{-1}$ & $6.18 \times 10^{-1}$ & 1.24 & $4.48 \times 10^{-8}$ & $9.32 \times 10^{-3}$ & $4.81 \times 10^{-6}$ \\
\hline $\begin{array}{c}20 \mathrm{mM} \text { Tris- } \\
\mathrm{HCl}\end{array}$ & 8 & 0 & 30 & $9.21 \times 10^{-6}$ & $3.04 \times 10^{-6}$ & 3.03 & $3.88 \times 10^{-1}$ & $5.97 \times 10^{-1}$ & $6.50 \times 10^{-1}$ \\
\hline
\end{tabular}

\section{CONCLUSION}

Modified Lumry Eyring model has been successfully used to fit the experimental data in those cases where aggregation was significant. It has been found that aggregation is significant in conditions pertaining to Protein A chromatography while in conditions typically employed in the bio-processing industry for Cation Exchange Chromatography and Anion Exchange Chromatography, aggregation is negligible in most cases. There was, however, one notable exception to this - aggregation was significant under conditions pertaining to Anion Exchange Chromatography in Tris- $\mathrm{HCl}$ buffer at a $\mathrm{pH}$ of 8 and temperature of $30^{\circ} \mathrm{C}$ in the absence of any salt. It can be inferred from this work that low $\mathrm{pH}$ and high temperature favor aggregation which is in agreement with the results reported in the literature. The presence of salt has been found to accelerate the rate of aggregation in most cases except one case in Tris-HCl buffer discussed earlier where it tends to retard aggregation. It has been found that dimer is the main aggregate species under these conditions. This work can be extended to the study of aggregation behavior of other monoclonal antibodies which can help identify general trends in the behavior of different mAbs and thus facilitate a better understanding of the aggregation process that would help in devising ingenious methods to combat it.

\section{REFERENCES}

[1] W. Wang, "Protein aggregation and its inhibition in biopharmaceutics," International Journal of Pharmaceutics, vol. 289, pp. 1-30, 2005

[2] J. S. Philo and T. Arakawa," Mechanisms of Protein Aggregation," Current Pharmaceutical Biotechnology, vol. 10, pp. 348-351, 2009.

[3] W. Wang, S. Nema, and D. Teagarden, "Protein aggregation Pathways and influencing factors," International Journal of Pharmaceutics, vol. 390, pp. 89-99, 2010.

[4] A. M. Morris, M. A. Watzky, and R. G. Finke, "Protein aggregation kinetics, mechanism, and curve fitting: A review of the literature," Biochimica et Biophysica Acta, vol. 1794, pp. 375-397, 2009.

[5] J. M. Andrews and C. J. Roberts, "A Lumry-Eyring nucleated polymerization model of protein aggregation kinetics: aggregation with pre-equilibrated unfolding," Journal of Physical Chemistry B, vol. 111, pp. 7897-7913, 2007.

[6] P. Arosio, G. Barolo, T. Müller-Späth, H. Wu, and M. Morbidelli, "Aggregation stability of a monoclonal antibody during downstream processing," Pharmaceutical Research, vol. 28, pp. 1884-1894, 2011.

[7] A. A. Shukla, P. Gupta, and X. Han, "Protein aggregation kinetics during Protein A chromatography. Case study for an $\mathrm{Fc}$ fusion protein," Journal of Chromatography A, vol. 1171, pp. 22-28, 2007.

[8] C. J. Roberts, "Non-native protein aggregation kinetics," Biotechnology and Bioengineering, vol. 98, pp. 927-938, 2007.

[9] C. J. Roberts, "Kinetics of Irreversible protein aggregation: analysis of extended Lumry-Eyring models and implications for predicting protein shelf life," Journal of Physical Chemistry B, vol. 107, pp. 1194-1207, 2003.
[10] P. Arosio, S. Rima, M. Lattuada, and M. Morbidelli, "Population balance modeling of antibodies aggregation kinetics," Journal of Physical Chemistry B, vol. 116, pp. 7066-7075, 2012.

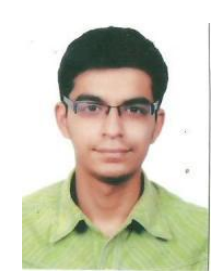

Ishan Arora is a senior B.Tech student in the Department of Chemical Engineering at the Indian Institute of Technology (IIT) Delhi, India. He is presently working in the field of Biochemical Engineering on aggregation of monoclonal antibodies. He has worked as a student intern in the Process Development Department at Haldor Topsoe A/S, Lyngby, Denmark. He has presented papers at various international and national conferences. Mr. Arora is a member of the Indian Institute of Chemical Engineers and Institution of Engineering and Technology (IET) London. He is a recipient of several academic awards such as HONDA Young Engineer and Scientist Award, NTSE Scholarship, KVPY Fellowship, Pearl Award, JSTSE Scholarship, NEST Scholarship etc. He is also a gold medalist at the national level in International Chemistry Olympiad.

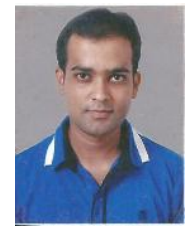

Rohit Bansal is a $\mathrm{Ph} . \mathrm{D}$. research scholar in the Department of Chemical Engineering at the Indian Institute of Technology Delhi. He is presently working under the guidance of Dr. Anurag S. Rathore on monoclonal antibody aggregation. He has completed his B.Tech in Biotechnology in 2010 from Amity University Noida and his M.Tech in Biotechnology in 2012 from Indian Institute of Technology Guwahati where he worked in the field of Molecular Biology.

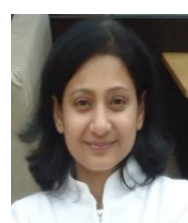

Varsha Joshi is a postdoctoral fellow in the Department of Chemical Engineering at the Indian Institute of Technology Delhi. Her current research is focused on studying the stability of monoclonal antibody products and its implications on processing. She has completed her B.Pharm in 2004 from Pune University, M.Tech in Bioprocess Technology in 2006 from Institute of Chemical Technology, Mumbai University and Ph.D. in Bioprocess Technology in 2010 from Institute of Chemical Technology, Mumbai University.

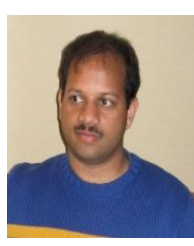

Anurag S. Rathore is a professor in the Department of Chemical Engineering at the Indian Institute of Technology (IIT) Delhi, India. He obtained his Ph.D. from Yale University, CT, USA, in 1998 and then worked in the Process Development groups at Pharmacia Corporation, St. Louis, USA, and Amgen, Inc., Thousand Oaks, USA before joining IIT Delhi in 2009.

Prof. Rathore is an active member of the Parenteral Drug Association (PDA) and American Chemical Society (ACS) and has authored more than 200 publications and presentations in these areas. He presently serves as the Editor-in-Chief of Preparative Biochemistry and Biotechnology and participates in the Editorial Advisory Boards for several international journals including PDA Journal of Pharmaceutical Science and Technology, Biotechnology Progress, BioPharm International, Pharmaceutical Technology Europe and Separation and Purification Reviews. Some of his current research areas are Process Analytical Technology (PAT) and Quality by Design (QbD), Characterization of biosimilar products, Stability of monoclonal antibody products etc. 